\title{
Maternal mental health and child problem behaviours: disentangling the role of depression and borderline personality dysfunction
}

Article

Published Version

Creative Commons: Attribution 4.0 (CC-BY)

Open access

Huntley, F., Wright, N., Pickles, A., Sharp, H. and Hill, J. (2017) Maternal mental health and child problem behaviours: disentangling the role of depression and borderline personality dysfunction. British Journal of Psychiatry Open, 3 (6). pp. 300305. ISSN 2056-4724 doi:

https://doi.org/10.1192/bjpo.bp.117.005843 Available at https://centaur.reading.ac.uk/74385/

It is advisable to refer to the publisher's version if you intend to cite from the work. See Guidance on citing.

To link to this article DOI: http://dx.doi.org/10.1192/bjpo.bp.117.005843

Publisher: Royal College of Psychiatrists

All outputs in CentAUR are protected by Intellectual Property Rights law, including copyright law. Copyright and IPR is retained by the creators or other copyright holders. Terms and conditions for use of this material are defined in the End User Agreement. 


\section{www.reading.ac.uk/centaur}

\section{CentAUR}

Central Archive at the University of Reading

Reading's research outputs online 
Maternal mental health and child problem behaviours: disentangling the role of depression and borderline personality dysfunction

Fay Huntley, Nicola Wright, Andrew Pickles, Helen Sharp and Jonathan Hill

\section{Background}

It is not known whether associations between child problem behaviours and maternal depression can be accounted for by comorbid borderline personality disorder (BPD) dysfunction.

\section{Aim \\ To examine the contributions of maternal depression and BPD symptoms to child problem behaviours.}

\section{Method}

Depression trajectories over the first-year postpartum were generated using repeated measurement

from a general population sample of 997 mothers recruited in pregnancy. In a stratified subsample of 251, maternal depression and BPD symptoms were examined as predictors of child problem behaviours at 2.5 years.

\section{Results}

Child problem behaviours were predicted by a high maternal depression trajectory prior to the inclusion of BPD symptoms. This association was no longer significant after the introduction of BPD symptoms.

\section{Conclusions}

Risks for child problem behaviours currently attributed to maternal depression may arise from more persistent and pervasive difficulties found in borderline personality dysfunction.

\section{Declaration of interest}

None.

\section{Copyright and usage}

(c) The Royal College of Psychiatrists 2017, this is an open access article distributed under the terms of the Creative Commons Attribution (CC BY) license.
Early-onset 'life course persistent' externalising child behaviours are associated with antisocial outcomes in adulthood and also with personality dysfunction and psychiatric disorders. ${ }^{1,2}$ They are therefore a major focus for early intervention. The association between maternal depression and child outcomes has received considerable research attention..$^{3-5}$ Maternal depression during the child's first year of life has been of particular interest because of concerns that exposure at this time may be particularly harmful through its influences on early mother-child interactions. ${ }^{6-8}$ Applications of longitudinal modelling techniques have enabled chronic exposures to depression, which may carry highest risk ${ }^{9-11}$ to be examined, and these have confirmed the link between maternal depression and child problem behaviours. ${ }^{9,12}$ Associations between maternal depression and child symptoms may, however, be confounded with other environmental and familial risks. ${ }^{3,13} \mathrm{~A}$ key question is whether associations could be better explained by mothers' personality dysfunction, specifically borderline personality disorder (BPD) pathology, both because of its high comorbidity with depression ${ }^{14,15}$ and because it is characterised by interpersonal dysfunction and emotional regulation difficulties that may impair parenting. ${ }^{16-18}$ Consistent with this possibility, elevated externalising and internalising symptoms were associated with questionnaire-based self-reports of maternal borderline, antisocial and narcissistic symptoms in a cross-sectional study of 4 -year-olds. ${ }^{19}$ No studies to date have examined prospectively the relative contributions of maternal depression over the postnatal period and BPD symptoms to young children's problem behaviours.

If risks to children associated with BPD dysfunction were confined to mothers meeting diagnostic criteria, then even strong associations with problem behaviours would be of limited relevance to the general population. The dimensional approach to personality disorder is likely to be more relevant and generalisable to community mother-child dyad samples, where rates of diagnosable personality disorder are likely to be low but there may be substantial variation in subthreshold symptoms. ${ }^{20}$ Dimensional approaches to the personality disorders have been widely used, ${ }^{21-23}$ and in the case of BPD, subthreshold levels of symptoms have been associated with a range of impairments. ${ }^{23-26}$

The aim of this study was to examine whether elevated maternal depressive symptoms over the first year of life predict child externalising behaviours at 2.5 years, and whether this association is explained by symptoms of BPD. Internalising and total problem scores were also examined in light of recent evidence that findings apparently specific to externalising symptoms may reflect associations with a broader set of symptoms or with general psychopathology 'p.'.

\section{Method}

\section{Sample}

Participants were members of the Wirral Child Health and Development Study, a prospective epidemiological longitudinal study starting in pregnancy. The study uses a two-stage stratified design in which a consecutive general population sample (the 'extensive' sample) is used to generate a smaller 'intensive' sample stratified by psychosocial risk and both are followed in tandem. The extensive sample was identified from consecutive first-time mothers who booked for antenatal care at the sole provider of universal prenatal care on the Wirral.

All women gave written informed consent at the point of recruitment in the antenatal clinic. Ethical approval for the study was granted by the Cheshire North and West Research Ethics Committee on 27 June 2006, reference number 05/Q1506/107. The cohort comprised 1233 mothers with surviving singleton babies. Mean age 
of the mothers at recruitment was 26.8 years (s.d. $=5.8$, range $18-51$ ), $41.8 \%$ of the extensive sample were in the most deprived quintile of UK neighbourhoods ${ }^{28}$ and $96.1 \%$ were White British. Of these, 997 reported on depression symptoms on at least two postnatal assessment occasions and made up the sample for trajectory analyses. Maternal responses to questions about psychological abuse in their current or recent partner relationship ${ }^{29}$ were used to generate the stratified intensive sample of mothers for more detailed study. The sample stratification has been described in more detail previously. ${ }^{30}$ There were 316 mothers recruited to the stratified intensive sample at 32 weeks' pregnancy. We focus here on the 251 mother-child dyads who completed the lab assessment when their children were 31.37 (s.d. $=2.50$ ) months old ('2.5 years'). Mothers providing information at 2.5 years were slightly older $($ mean $=27.9$ years, s.d. $=6.2$, range $18-51$ ) and less deprived (37.8\% in most deprived quintile) than the original extensive sample.

\section{Measures}

\section{Maternal depression}

Exposure to maternal depression was assessed by self-report using the Edinburgh Postnatal Depression Scale ${ }^{31}$ (EPDS) at 5, 9 and 29 weeks, and 14 months, and these scores were used to generate depression trajectories. The EPDS from age 2.5 years was also used in analyses to control for possible biasing of maternal reports of child problems.

\section{Maternal BPD symptoms}

Maternal BPD symptoms were assessed using the Structured Clinical Interview for DSM-IV Axis II Disorders ${ }^{32}$ (SCID-II). The SCID-II was administered when mothers were 32 weeks pregnant to assess symptoms of four personality disorders: borderline, antisocial, dependent and avoidant. Only BPD symptoms were examined in this study. Presence or absence of each symptom is initially assessed using a screening questionnaire (administered in this study at 20 weeks), and this is followed by a semi-structured interview to elicit further information regarding the extent each symptom has been persistent and pervasive over the previous 5 years, and whether it has caused functional impairment. Dimensional scores for maternal BPD were derived by summing the scores for each item: scored 1 (absent), 2 (subthreshold) and 3 (present). ${ }^{33}$ Scores ranged from 9 to 19 . Ratings were made from audio recordings. The first author was trained to reliability in scoring the SCID-II and had experience of using it in a range of clinical and community samples. Interrater reliability based on 20 audio recordings from this study was high (intraclass correlation coefficient $=0.91$ ).

\section{Child problem behaviours}

Maternal report of child problem behaviours was assessed at 2.5 years using the preschool Child Behavior Checklist (CBCL), which has been extensively used in studies of child and adolescent emotional and behavioural disorders. ${ }^{34}$ It has 99 items, each scored 0 (not true), 1 (somewhat or sometimes true) and 2 (very true or often true), which are summed to create seven syndrome scales. Syndrome scales for externalising, internalising and total problem behaviours were used. Raw scores were used for analysis.

\section{Stratifier and potential confounders}

\section{Maternal negative emotionality}

Maternal negative emotionality was assessed using the negative temperament scale from the Schedule for Nonadaptive and Adaptive
Personality (SNAP). SNAP negative emotionality is strongly associated with measures of neuroticism. ${ }^{35}$

\section{Child negative emotionality}

Infant negative emotionality was assessed at 29 weeks and 14 months by maternal report using the distress to limitations and fear subscales of the Infant Behavioral Questionnaire - Revised (IBQ-R). ${ }^{36}$ The two subscales are combined and a mean score is used for analysis. The IBQ-R has established reliability and validity and has been widely used in developmental studies. ${ }^{37,38}$

\section{Partner psychological abuse}

Partner psychological abuse, used in the sample stratification, was assessed using a 20 -item questionnaire covering humiliating, demeaning or threatening utterances in the partner relationship during pregnancy over the previous year. ${ }^{29}$ All participants scoring above the threshold on the measure of psychological abuse at 20 weeks' gestation were eligible for inclusion in the intensive sample, plus a random selection from those below. Within the intensively assessed stratified subsample, $51 \%$ were drawn from the women with high psychosocial risk and $49 \%$ from those with low psychosocial risk. A variable indicating whether the mother was high or low psychosocial risk allocation to the intensive sample was included to account for the sample stratification to allow for the generalisation of results to the general population.

\section{Demographic variables}

Demographic variables known to be associated with maternal depression and child mental health disorders were: maternal age at first pregnancy, education ( $0=$ left education age 18 or younger, $1=$ left education after age 18), marital status $(0=$ single or with partner living elsewhere, $1=$ married or cohabiting) and socioeconomic status assessed at recruitment at 20 weeks' pregnancy. Socioeconomic status was determined using the revised English Index of Multiple Deprivation ${ }^{28}$ (IMD) and converted to quintile categories with a binary variable ( $1=$ most deprived, $0=$ all 4 other quintiles) used for analysis.

\section{Statistical analysis}

Longitudinal latent class analysis (LLCA) was used to characterise maternal depression as it provides a method to identify and summarise patterns present in symptoms measured longitudinally. ${ }^{20,39}$ An advantage of LLCA compared with other group-based modelling techniques is that it is not based on the assumption of continuous, normal distribution. Instead, it is assumed that classes may follow different courses that vary over time and therefore allow for irregularity and change. ${ }^{40}$ The approach is well suited to data from prospective studies as it is based on the 'maximum likelihood function' that allows for data missing at random to be included. ${ }^{41}$ In LLCA, a larger sample size is preferable in order to increase the accuracy of hypothesised groups. ${ }^{42}$ Therefore, we used data from the 1233 extensive sample to model mothers' depressive symptoms across the first year. Of the sample, 997 had reported on their depressive symptoms during the first year on at least two occasions.

As is common in community samples, maternal depression scores in this study were highly skewed. Such distributions can lead to biased model estimates and unreliable fit statistics. ${ }^{39}$ To address this, the use of ordinal variables to represent the actual distribution of scores has been recommended. ${ }^{41}$ Therefore, four ordinal categories were created to use in the LLCA based on the frequency distributions of mothers' depression scores at each assessment point. 
We performed LLCA using Mplus, Version $4.1 .^{43}$ In LLCA, models are specified and fitted successively, with fit to the data tested against several fit indices as recommended in the literature. ${ }^{39}$ Models were evaluated on the basis of the Bayesian Information Criteria (BIC), entropy and the Lo-Mendell-Rubin likelihood ratio test (LMR-B). Lower BIC and higher entropy values indicate more accurate classification. ${ }^{41} \mathrm{~A}$ significant LMR-B indicates that the addition of a further class has made a significant improvement to the model as compared with the class solution that comes before it. After the model is chosen, participants are assigned to their most likely class according to which they receive the highest posterior probability for. A variable representing this assignment is then used to examine predictions from class membership to hypothesised outcomes.

CBCL externalising, internalising and total problems scores were skewed, and this was corrected using a log transformation. Hypothesis testing proceeded in three steps. In the first step, we examined associations between the confounders, maternal depression trajectory and child problems in multiple linear regression. Dummy variables were used that represented the mother's most likely class membership, with the 'very low' class as the reference group. In the second step, the effect of adding maternal negative emotionality was examined. In the third step, the effect of adding BPD symptoms was examined. Maternal depression at 2.5 years, which may introduce reporting bias for child symptoms, was not included initially as it may also be a mediator of depression effects. However, final analyses were repeated including maternal depression scores at follow-up.

\section{Results}

\section{LLCA model choice}

Models with between two and six classes were estimated. Fit indices for each are presented in Table 1. Examination of the BIC, entropy and LMR-B significance suggested that the three-class model was the most adequate fit to the data. This model had the lowest BIC value, indicating a better fit to the data. Entropy of 0.72 suggested 'medium' classification accuracy, and the highly significant LMR-B test suggested that the three-class model was a significant improvement in fit as compared to the two-class model. The three-class model also had the highest mean posterior probabilities, further supporting this selection. The three-class model included a 'high' class $(20.0 \%)$ made up of mothers whose posterior probability of scoring $>10$ on the EPDS was at least 0.5 or higher at all of the assessment points, an 'intermediate' class (33.4\%) that had relatively low probabilities of scoring $>10$ on the EPDS (0-0.25) across the assessment points and a 'very low' class (46.6\%) where mothers had consistently low probabilities $(<0.1)$ of scoring $>10$ on the EPDS across all assessment points. Extraction of class membership for the 251 mothers who had provided outcome data at 2.5 years yielded 42 mothers in the high trajectory, 119 mothers in the intermediate trajectory and 90 mothers who followed the very low trajectory.

\begin{tabular}{|lcccc|}
\hline \multicolumn{5}{|l|}{ Table 1 Fit statistics for each model estimated using LLCA } \\
\hline Model & BIC & Entropy & LMR-B & LMR-B P \\
\hline Two-Class & 5752.16 & 0.60 & 390.82 & $<0.001$ \\
\hline Three-class & 5668.10 & 0.72 & 131.07 & $<0.001$ \\
\hline Four-class & 5683.58 & 0.69 & 32.63 & 0.026 \\
\hline Five-Class & 5713.59 & 0.70 & 18.27 & 0.072 \\
\hline Six-Class & 5749.99 & 0.63 & 12.53 & 1.00 \\
\hline $\begin{array}{l}\text { LLCA, longitudinal latent Class analysis; BIC, sample size adjusted Bayesian } \\
\text { Information Criterion; LMR-B, Lo-Mendell-Rubin likelihood ratio test. }\end{array}$ \\
\hline
\end{tabular}

\section{Descriptive statistics}

The simple correlations and summary statistics for all the variables are presented in Table 2. Spearman's Rank correlations were used throughout for continuous variables, with polychoric and tetrachoric correlations used where appropriate for ordinal and binary variables. It can be seen that maternal BPD symptoms were significantly associated with being younger at the birth of the first child, with less education, with single parent status, elevated deprivation and infant negative emotionality. Maternal BPD symptoms were also associated with membership of the high depression trajectory and maternal negative emotionality. Both maternal depression class and BPD symptoms were associated with child externalising, internalising and total problem behaviours. Maternal depression at the time of reporting was also significantly associated with the three child outcomes.

\section{Prediction of child externalising, internalising and total problem behaviours}

The regression models for externalising, internalising and total child problem behaviours are shown in Table 3. In the first step, for all three outcomes and after controlling for confounders, infant negative emotionality and the high maternal depression trajectory made independent contributions to child symptoms. For each outcome, there was a modest but statistically non-significant effect of adding maternal negative emotionality to the model, and this also led to some attenuation of the contributions of infant negative emotionality and maternal high depression.

With the introduction of maternal BPD symptoms in the third step, the contribution of the depression trajectory was substantially reduced for all three CBCL outcomes. In the models for externalising and total problems, with the addition of BPD symptoms the contribution of maternal depression trajectory became non-significant. BPD symptoms explained an additional $4 \%$ of variance in child externalising problems, $3 \%$ in child internalising problems and $4 \%$ in total behaviour problems. The analyses were rerun including mothers' EPDS scores at age 2.5 years to account for possible reporting bias, and the findings were unchanged.

\section{Discussion}

In a prospective study of parents and children recruited from the general population, an elevated trajectory of maternal depression symptoms over the first year of life, postpartum, predicted higher child externalising, internalising and total problems as reported by mothers at 2.5 years. However, maternal depression trajectory was associated with elevated BPD symptoms identified during pregnancy. This entirely explained the association between maternal depression symptoms and externalising and total problems. For internalising problems, maternal depression symptoms remained a significant predictor.

The finding in this study of an association between maternal depression and child externalising problems is consistent with evidence from a wide range of previous studies. ${ }^{9-11}$ Of particular relevance, Cents and colleagues, ${ }^{12}$ using a similar modelling approach in a general population study, showed that elevated maternal depression trajectories during infancy were associated with higher child externalising problems. There were also some differences, in that trajectories were derived from measurement over a greater time period from pregnancy up to 36 months postnatally and four trajectories were identified, three of which were associated with child symptoms. Previous studies of maternal depression, however, have not examined for the additional contribution of BPD symptoms. 


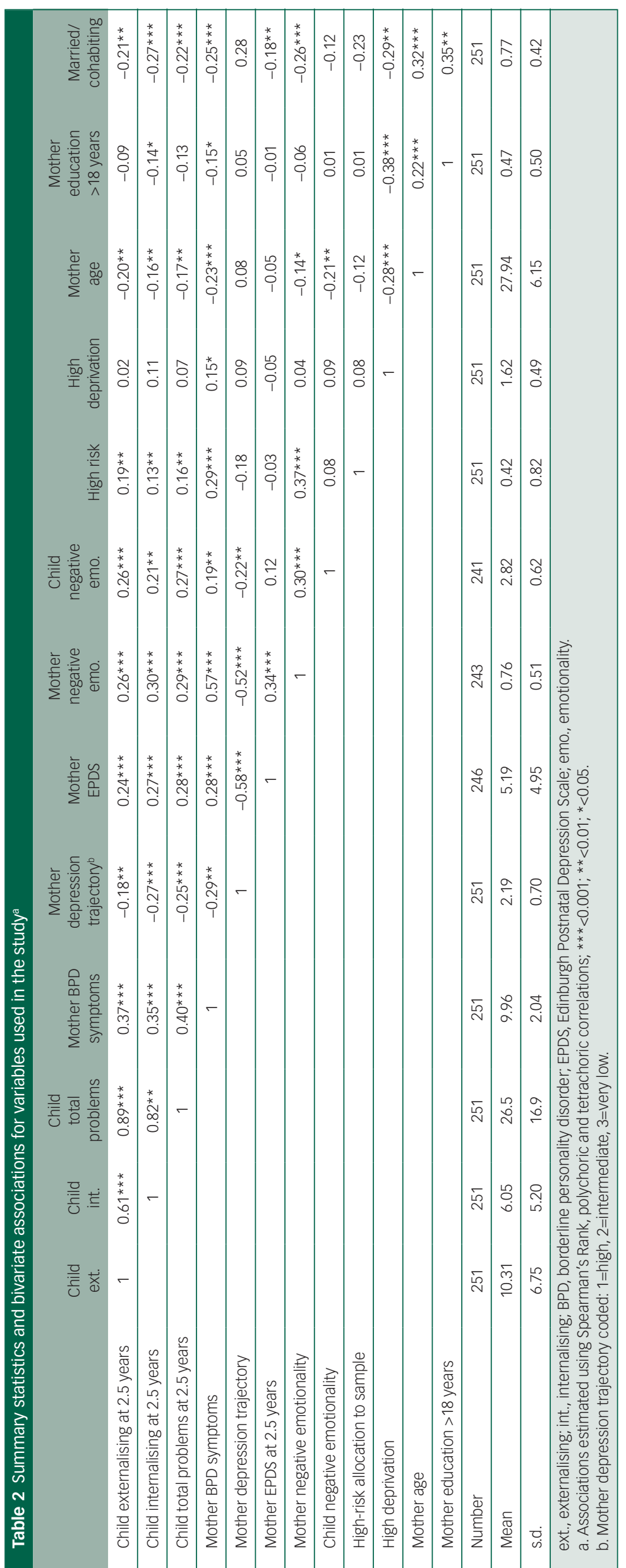




\begin{tabular}{|c|c|c|c|c|c|c|}
\hline & \multicolumn{2}{|c|}{$\mathrm{CBCL}$ total problems } & \multicolumn{2}{|c|}{$\mathrm{CBCL}$ externalising problems } & \multicolumn{2}{|c|}{$\mathrm{CBCL}$ internalising problems } \\
\hline & $\beta(\mathrm{Cl})$ & $P$ & $\beta(\mathrm{Cl})$ & $P$ & $\beta(\mathrm{Cl})$ & $P$ \\
\hline Step 1 & $\Delta R^{2}=0.15$ & & $\Delta R^{2}=0.12$ & & $\Delta R^{2}=0.18$ & \\
\hline Negative emotionality - infant & 0.19 (0.06 to 0.30$)$ & 0.004 & 0.14 (0.01 to 0.19$)$ & 0.035 & 0.18 (0.07 to 0.38$)$ & 0.005 \\
\hline High depression trajectory - mother & 0.22 (0.13 to 0.58$)$ & 0.002 & 0.17 (0.04 to 0.37$)$ & 0.017 & 0.25 (0.24 to 0.80$)$ & $<0.001$ \\
\hline Intermediate depression trajectory - mother & $0.13(-0.01$ to 0.31$)$ & 0.069 & $0.07(-0.06$ to 0.18$)$ & 0.302 & $0.12(-0.03$ to 0.39$)$ & 0.089 \\
\hline Step 2 & $\Delta R^{2}=0.01$ & & $\Delta R^{2}=0.01$ & & $\Delta R^{2}=0.01$ & \\
\hline Negative emotionality - infant & 0.18 (0.04 to 0.29$)$ & 0.008 & $0.12(-0.01$ to 0.17$)$ & 0.066 & 0.17 (0.05 to 0.36$)$ & 0.010 \\
\hline High depression trajectory - mother & 0.17 (0.01 to 0.52) & 0.042 & $0.11(-0.06$ to 0.31$)$ & 0.178 & 0.20 (0.09 to 0.74 ) & 0.012 \\
\hline Intermediate depression trajectory - mother & 0.09 (-0.06 to 0.28$)$ & 0.211 & $0.03(-0.10$ to 0.16$)$ & 0.643 & $0.09(-0.09$ to 0.35$)$ & 0.238 \\
\hline Negative emotionality - mother & $0.12(-0.04$ to 0.32$)$ & 0.134 & $0.13(-0.02$ to 0.24$)$ & 0.105 & $0.11(-0.07$ to 0.39$)$ & 0.168 \\
\hline Step 3 & $\Delta R^{2}=0.04$ & & $\Delta R^{2}=0.04$ & & $\Delta \mathrm{R}^{2}=0.03$ & \\
\hline Negative emotionality - infant & 0.17 (0.05 to 0.28$)$ & 0.174 & $0.12(-0.01$ to 0.17$)$ & 0.064 & $0.17(0.05$ to 0.36$)$ & 0.010 \\
\hline High depression trajectory - mother & $0.14(-0.02$ to 0.47$)$ & 0.074 & $0.09(-0.08$ to 0.29$)$ & 0.272 & 0.18 (0.06 to 0.69$)$ & 0.021 \\
\hline Intermediate depression trajectory - mother & $0.11(-0.04$ to 0.29$)$ & 0.106 & $0.05(-0.08$ to 0.16$)$ & 0.522 & $0.10(-0.07$ to 0.36$)$ & 0.181 \\
\hline Negative emotionality - mother & $-0.02(-0.23$ to 0.17$)$ & 0.790 & $-0.01(-0.15$ to 0.14$)$ & 0.956 & $-0.01(-0.26$ to 0.25$)$ & 0.964 \\
\hline Borderline personality disorder symptoms - mother & 0.27 (0.03 to 0.12$)$ & 0.001 & $0.26(0.02$ to 0.08$)$ & 0.002 & 0.21 (0.02 to 0.13$)$ & 0.007 \\
\hline
\end{tabular}

\section{Strengths and limitations}

Strengths of the study included prospective examination of maternal depression and BPD symptoms in a sample identified from the general population, and accounting for a number of plausible confounds, including infant temperament assessed as negative emotionality, and maternal negative emotionality, a measure of neuroticism. BPD symptoms were assessed in interview and rated independently of reports of child symptoms, and so were not open to effects of shared method variance, which may limit interpretation of associations between self-report measures. A limitation of the measurement of the outcome was that ratings were available only from one informant. Although this is common in studies of emotional and behavioural outcomes in young children, information from further informants may have given different findings. The study was limited also in not being able to account for shared genetic influences on BPD symptoms and child emotional and behavioural problems, and there may be further confounds for BPD symptoms that were not assessed. ${ }^{44}$ Participants were recruited from a geographical area with few ethnic minority families and high levels of socioeconomic deprivation, which may limit the generalisability of the findings.

\section{Implications}

The potential importance of maternal personality dysfunction was identified more than 30 years ago in a prospective study of the children of psychiatric patients, ${ }^{45}$ but it has received relatively little attention since then. A recent review of studies of BPD, parenting and child adjustment found substantial evidence for reduced maternal sensitivity and increased intrusiveness associated with maternal BPD, which may contribute to increased risk for child psychopathology. ${ }^{18}$ However, evidence regarding links with externalising and internalising problems in early life is very limited. If the associations reported here do reflect a causal link, a major challenge will be to identify specific components of BPD that may have an impact on child adjustment. A central feature of BPD is interpersonal and emotion regulation difficulties ${ }^{46}$ that are likely to negatively affect the mother-child relationship and parenting behaviours. ${ }^{23,47,48}$ This may be particularly important in the early years, given the prominence and salience of the mother-child relationship. ${ }^{49}$ Associations between maternal BPD symptoms and maternal behaviours with infants such as role confusion and disoriented behaviours may be particularly relevant because of their association with disorganised attachment. ${ }^{50}$ Effects may also arise from associated difficulties such as relationships with partners with personality dysfunction and marital discord. ${ }^{45}$ A key implication for early preventative and treatment interventions is that maternal postnatal depression may be the wrong focus and that even earlier support for pregnant mothers with personality difficulties may be more relevant.

Fay Huntley, ClinPsyD, PhD, Department of Psychological Sciences, Institute of Psychology, Health and Society, , University of Liverpool, UK; Nicola Wright, BSC, MSC, Department of Psychological Sciences, Institute of Psychology, Health and Society, University of Liverpool, UK; Andrew Pickles, FMedSci, Professor, Biostatistics Department, Institute of Psychiatry, Psychology and Neuroscience, King's College London, London, UK; Helen Sharp, DClinPsy, PhD, Department of Psychological Sciences, Institute of Psychology, Health and Society, University of Liverpool, Liverpool, UK; Jonathan Hill,FRCPsych, Professor, School of Psychology and Clinical Language Sciences, University of Reading, Reading, UK

Correspondence: Nicola Wright, School of Psychology, University of Liverpool, Eleanor Rathbone Building, Bedford Street South, Liverpool L69 7ZA, UK. Email: n.j.wright@liverpool.ac.uk

First received 4 Sep 2017, accepted 30 Oct 2017

\section{Funding}

The research was funded by grants from the UK Medical Research Council (G0900654; G0400577).

\section{Acknowledgements}

We are grateful to all participating families and research staff who contributed to this work. We also thank Wirral University Teaching Hospital NHS Foundation Trust, Cheshire, and Wirral Partnership NHS Foundation Trust, Wirral Community NHS Trust and the National Institute for Health Research (NIHR) Biomedical Research Centre at South London and Maudsley NHS Foundation Trust. 


\section{References}

1 Moffitt TE, Caspi A, Harrington H, Milne BJ. Males on the life-course-persistent and adolescence-limited antisocial pathways: follow-up at age 26 years. Dev Psychopathol 2002; 14: 179-207.

2 Odgers CL, Moffitt TE, Broadbent JM, Dickson N, Hancox RJ, Harrington H, et al. Female and male antisocial trajectories: from childhood origins to adult outcomes. Dev Psychopathol 2008; 20: 673-716.

3 Goodman SH, Rouse MH, Connell AM, Broth MR, Hall CM, Heyward D. Maternal depression and child psychopathology: a meta-analytic review. Clin Child Fam Psychol Rev 2011; 14: 1-27.

4 Kim-Cohen J, Moffitt TE, Taylor A, Pawlby SJ, Caspi A. Maternal depression and children's antisocial behavior: nature and nurture effects. Arch Gen Psychiatry 2005; 62: 173-81.

5 Weissman MM, Pilowsky DJ, Wickramaratne PJ, Talati A, Wisniewski SR, Fava M, et al. Remissions in maternal depression and child psychopathology: a STAR* D-child report. JAMA 2006; 295:1389-98.

6 Field T. Postpartum depression effects on early interactions, parenting, and safety practices: a review. Infant Behav Dev 2010; 33: 1-6.

7 Goodman SH, Gotlib IH (eds). Children of Depressed Parents: Mechanisms of Risk and Implications for Treatment. American Psychological Association, 2002.

8 Murray L, Fiori-Cowley A, Hooper R, Cooper P. The impact of postnatal depression and associated adversity on early mother-infant interactions and later infant outcome. Child Dev 1996; 1: 2512-26.

9 Campbell FA, Pungello EP, Burchinal M, Kainz K, Pan Y, Wasik BH, et al. Adult outcomes as a function of an early childhood educational program: an Abecedarian Project follow-up. Dev Psychol 2012; 48: 1033-43.

10 Hammen C, Brennan PA. Severity, chronicity, and timing of maternal depression and risk for adolescent offspring diagnoses in a community sample. Arch Gen Psychiatry 2003; 60: 253-8.

11 Matijasevich A, Murray J, Cooper PJ, Anselmi L, Barros AJ, Barros FC, et al. Trajectories of maternal depression and offspring psychopathology at 6 years: 2004 Pelotas cohort study. J Affect Disord 2015; 174: 424-31.

12 Cents RA, Diamantopoulou S, Hudziak JJ, Jaddoe VW, Hofman A, Verhulst FC, et al. Trajectories of maternal depressive symptoms predict child problem behaviour: the generation R study. Psychol Med 2013; 43: 13-25.

13 Barker ED, Copeland W, Maughan B, Jaffee SR, Uher R. Relative impact of maternal depression and associated risk factors on offspring psychopathology. $\mathrm{Br}$ 」 Psychiatry 2012; 200: 124-9.

14 Friborg $\mathrm{O}$, Martinsen EW, Martinussen $\mathrm{M}$, Kaiser $\mathrm{S}$, Øvergård $\mathrm{KT}$, Rosenvinge $\mathrm{JH}$. Comorbidity of personality disorders in mood disorders: a meta-analytic review of 122 studies from 1988 to 2010. J Affect Disord 2014; 152: 1-11.

15 Hirschfeld R. Personality disorders and depression: comorbidity. Depress Anxiety 1999; 10: 142-6.

16 Carpenter RW, Trull TJ. Components of emotion dysregulation in borderline personality disorder: a review. Curr Psychiatry Rep 2013; 15: 335

17 Eyden J, Winsper C, Wolke D, Broome MR, MacCallum F. A systematic review of the parenting and outcomes experienced by offspring of mothers with borderline personality pathology: potential mechanisms and clinical implications. Clin PSychol Rev 2016; 47: 85-105.

18 Petfield L, Startup H, Droscher H, Cartwright-Hatton S. Parenting in mothers with borderline personality disorder and impact on child outcomes. Evid Based Ment Health 2015; 18: 67-75.

19 Berg-Nielsen TS, Wichström L. The mental health of preschoolers in a Norwegian population-based study when their parents have symptoms of borderline, antisocial, and narcissistic personality disorders: at the mercy of unpredictability. Child Adolesc Psychiatry Ment Health 2012; 6: 19.

20 Pickles A, Angold A. Natural categories or fundamental dimensions: on carving nature at the joints and the rearticulation of psychopathology. Dev Psychopathol 2003; 15: 529-51.

21 Skodol AE, Gunderson JG, Shea MT, MCGlashan TH, Morey LC, Sanislow CA, et al. The collaborative longitudinal personality disorders study (CLPS): overview and implications. J Personal Disord 2005; 19: 487-504.

22 Trull TJ, Durrett CA. Categorical and dimensional models of personality disorder. Annu Rev Clin Psychol 2005; 1: 355-80.

23 Hill J, Pilkonis P, Morse J, Feske U, Reynolds $\mathrm{S}$, Hope H, et al. Social domain dysfunction and disorganization in borderline personality disorder. Psychol Med 2008; 38 : $135-46$.

24 Bagge C, Nickell A, Stepp S, Durrett C, Jackson K, Trull TJ. Borderline personality disorder features predict negative outcomes 2 years later. J Abnorm Psychol 2004; 113: $279-88$.
25 Morgan TA, Chelminski I, Young D, Dalrymple K, Zimmerman M. Is dimensional scoring important only for subthreshold levels of severity in personality disorders other than borderline? Compr Psychiatry 2013; 54: 673-9.

26 Zimmerman M, Chelminski I, Young D, Dalrymple K, Martinez J. Is dimensional scoring of borderline personality disorder important only for subthreshold levels of severity? J Pers Disord 2013; 27: 244-51.

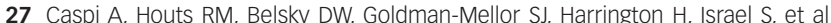
The $p$ factor: one general psychopathology factor in the structure of psychiatric disorders? Clin Psychol Sci 2014; 2: 119-37.

28 Noble M, Wright G, Dibbon C, Smith G, Mclennan D, Antila C. The English Indices of Deprivation 2004 (Revised). Report to the Office of the Deputy Prime Minister Neighbourhood Renewal Unit, 2004.

29 Moffitt TE, Caspi A, Krueger RF, Magdol L, Margolin G, Silva PA, et al. Do partners agree about abuse in their relationship?: a psychometric evaluation of interpartner agreement. Psychol Assess 1997; 9: 47-56.

30 Sharp H, Pickles A, Meaney M, Marshall K, Tibu F, Hill J. Frequency of infant stroking reported by mothers moderates the effect of prenatal depression on infant behavioural and physiological outcomes. PLOS One 2012; 7: e45446.

31 Cox JL, Chapman G, Murray D, Jones P. Validation of the Edinburgh Postnatal Depression Scale (EPDS) in non-postnatal women. J Affect Disord 1996; 39: 185-9.

32 First MB, Gibbon M, Spitzer RL, Smith Benjamin L. User's Guide for the Structured Clinical Interview for DSM-IV Axis II Personality Disorders: SCID-II. American PSychiatric Press, 1997.

33 Chanen AM, Jovev M, Djaja D, McDougall E, Yuen HP, Rawlings D, et al. Screening for borderline personality disorder in outpatient youth. J Personal Disord 2008; 22 353-64.

34 Achenbach TM, Rescorla LA. Manual for the ASEBA Preschool Forms and Profiles. University of Vermont, Research Center for Children, Youth and Families, 2000.

35 Reynolds SK, Clark LA. Predicting dimensions of personality disorder from domains and facets of the five factor model. J Pers 2001; 69: 199-222.

36 Gartstein MA, Rothbart MK. Studying infant temperament via the revised infant behavior questionnaire. Infant Behav Dev 2003; 26: 64-86.

37 Gagne JR, Goldsmith HH. A longitudinal analysis of anger and inhibitory control in twins from 12 to 36 months of age. Dev Sci 2011; 14: 112-24.

38 Parade $\mathrm{SH}$, Leerkes EM. The reliability and validity of the infant behavior questionnaire-revised. Infant Behav Dev 2008; 31: 637-46.

39 Nagin DS, Odgers CL. Group-based trajectory modeling in clinical research. Annu Rev Clin Psychol 2010; 6: 109-38.

40 Nagin DS, Tremblay RE. Analyzing developmental trajectories of distinct but related behaviors: a group-based method. Psychol Methods 2001; 6: 18-34.

41 Nagin DS. Group-Based Modeling of Development. Harvard University Press, 2009.

$42 \mathrm{Kim}$ SY. Determining the number of latent classes in single-and multiphase growth mixture models. Struct Equ Modeling 2014; 21: 263-79.

43 Muthen LK, Muthén B. Mplus User's Guide, v 4.1. Muthen \& Muthen, UCLA 1998-2005

44 Jaffee SR, Strait LB, Odgers CL. From correlates to causes: can quasi-experimental studies and statistical innovations bring us closer to identifying the causes of antisocial behavior? Psychol Bull 2012; 138: 272-95.

45 Rutter M, Quinton D. Parental psychiatric disorder: effects on children. Psychol Med 1984; 14: 853-80.

46 Alwin N, Blackburn R, Davidson K, Hilton M, Logan C, Shine J. Understanding Personality Disorder: A Report by the British Psychological Society. The British Psychological Society, 2006.

47 Conroy S, Marks MN, Schacht R, Davies HA, Moran P. The impact of maternal depression and personality disorder on early infant care. Soc Psychiatry Psychiatr Epidemiol 2010; 45: 285-92.

48 Stepp SD, Whalen DJ, Pilkonis PA, Hipwell AE, Levine MD. Children of mothers with borderline personality disorder: identifying parenting behaviors as potential targets for intervention. Pers Disord 2012; 3: 76-91.

49 Kochanska G, Friesenborg AE, Lange LA, Martel MM. Parents' personality and infants' temperament as contributors to their emerging relationship. J Pers Soc Psychol 2004; 86: 744-59.

50 Lyons-Ruth K, Brumariu LE, Bureau, JF, Hennighausen K, Holmes B. Role confusion and disorientation in young adult-parent interaction among individuals with borderline symptomatology. J Pers Disord 2015; 29: 641-62. 


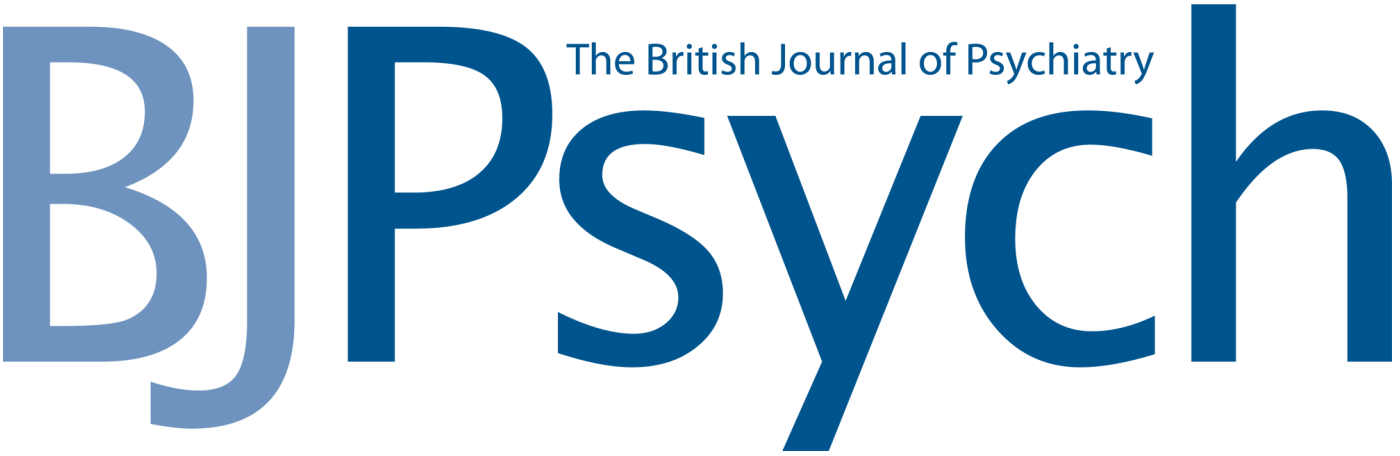

Maternal mental health and child problem behaviours: disentangling the role of depression and borderline personality dysfunction

Fay Huntley, Nicola Wright, Andrew Pickles, Helen Sharp and Jonathan Hill Br J Psychiatry Open 2017, 3:300-305.

Access the most recent version at DOI: 10.1192/bjpo.bp.117.005843

References This article cites 43 articles, 2 of which you can access for free at: http://bjpo.rcpsych.org/content/3/6/300\#BIBL

Reprints/ To obtain reprints or permission to reproduce material from this paper, please permissions write to permissions@rcpsych.ac.uk

You can respond /letters/submit/bjporcpsych;3/6/300

to this article at

Downloaded http://bjpo.rcpsych.org/ on January 2, 2018

from Published by The Royal College of Psychiatrists 